\title{
Vaginal cuff brachytherapy practice in endometrial cancer patients: a report from the Turkish Oncology Group
}

\author{
Prof. Yasemin Bolukbasi, MD',2, Cem Onal ${ }^{3}$, Zeynep Ozsaran ${ }^{4}$, Sukran Senyurek!, Eyub Yasar Akdemir', Ugur Selek!, \\ Ferah Yildiz \\ 'Department of Radiation Oncology, Faculty of Medicine, Koç University, Istanbul, Turkey, ${ }^{2}$ Department of Radiation Oncology, The University \\ of Texas, MD Anderson Cancer Center, Houston, TX, USA, ${ }^{3}$ Department of Radiation Oncology, Faculty of Medicine, Başkent University, \\ Adana Dr Turgut Noyan Research and Treatment Center, Adana, Turkey, ${ }^{4}$ Department of Radiation Oncology, Faculty of Medicine, \\ Ege University, Izmir, Turkey, ${ }^{5}$ Department of Radiation Oncology, Faculty of Medicine, Hacettepe University Ankara, Turkey
}

\begin{abstract}
Purpose: The American Brachytherapy Association is attempting to develop standards for delivering brachytherapy, although differences in practice have been reported in the literature. This study evaluated vaginal cuff brachytherapy (VBT) practice and quality of life-related recommendations among Turkish radiation oncologists.

Material and methods: A nationwide web-based 17-item survey was distributed to the members of the Turkish Society for Radiation Oncology. These members received e-mail notifications, and a link was posted on the Turkish Society for Radiation Oncology internet site to solicit voluntary responses The survey addressed the simulation processes, target volume, prescribed dose, delivery schedules, and recommendations related to vaginal side effects.

Results: Fifty-seven radiation oncologists responded to the survey. The most used dose fraction schemes for adjuvant VBT were 7 Gy $\times 3$ fractions (30\%), 5.5 Gy $\times 5$ fractions $(26 \%)$, and 6 Gy $\times 5$ fractions (28\%). The preferred VBT scheme was $5 \mathrm{~Gy} \times 3$ fractions (50\%) when the external beam radiotherapy (EBRT) dose was 45 Gy external radiotherapy, while the preferred schemes were $6 \mathrm{~Gy} \times 3$ fractions $(30 \%)$ or $5 \mathrm{~Gy} \times 3$ fractions (32\%) when the external radiotherapy dose was increased to $50.4 \mathrm{~Gy}$. One-half of the respondents delivered VBT twice a week, and the dose was prescribed to $0.5 \mathrm{~cm}$ from vaginal mucosa by $86 \%$ of the respondents. There was no common definition for the dose prescription length, which was defined as $3 \mathrm{~cm}$ from the vaginal cuff in $33 \%$ of responses and as $4 \mathrm{~cm}$ in $35 \%$ of responses. For serous and clear cell histological types, $38 \%$ of the respondents targeted "full cylinder length". To prevent vaginal side effects, $78 \%$ of the respondents recommended using a vaginal dilator and/or sexual intercourse after VBT.

Conclusions: This survey revealed variations in the clinical practice of VBT among Turkish radiation oncologists, which suggests that standardization is necessary.
\end{abstract}

J Contemp Brachytherapy 2021; 13, 2: 152-157 DOI: https://doi.org/10.5114/jcb.2021.105282

Key words: brachytherapy, vaginal cuff, experience, survey.

\begin{abstract}
Purpose
Endometrial cancer (EC) is the most common gynecological malignancy. In the era of comprehensive pelvic and paraaortic lymphadenectomy, vaginal cuff brachytherapy (VBT) provides high local control rates with minimal toxicity for early-stage disease [1]. PORTEC-2 trial revealed that VBT alone could be a less toxic alternative to external radiotherapy (RT) for intermediate- to high-risk EC [2]. Furthermore, analysis of data from the surveillance, epidemiology, and end results database revealed a trend toward an increased use of VBT alone for patients with early-stage EC [3]. However, there is a significant
\end{abstract}

benefit associated with combining VBT and pelvic RT for select patients, especially those with advanced-stage disease [4].

The American Brachytherapy Society (ABS) has published a guideline with recommendations and indications regarding the use of VBT for patients with EC [5]. In the early 2000s, that report highlighted the use of high-doserate (HDR) brachytherapy and eventually helped standardize the use of brachytherapy, with updates published in 2012 [5, 6]. Based on these guidelines, American radiation oncologists and ABS members were surveyed in 2005 and 2015 regarding their use of post-operative VBT [7-9]. The survey results showed some variability,
Address for correspondence: Prof. Yasemin Bolukbasi, MD, Department of Radiation Oncology, Faculty of Medicine, Koç University, Davutpasa Caddesi, No. 4, 34010 Topkapi, Istanbul, Turkey, e-mail: ybolukbasi@kuh.ku.edu.tr
Received: 12.05 .2020

Accepted: 22.01 .2021

Published: 14.04 .2021 
although the use of VBT was generally aligned with the ABS recommendations [7, 8, 10]. Moreover, an Italian survey was performed in 2016 to examine the current practice of VBT and external beam RT based on the latest technological developments, such as image-guided adaptive brachytherapy and RT [11]. Therefore, we performed a survey to evaluate the use of adjuvant VBT for patients with EC in Turkey.

\section{Material and methods}

During January 2017, four experienced radiation oncologists (YB, FY, ZO, and $\mathrm{CO}$ ) who are specialized in brachytherapy, developed a survey as a part of the Gynecological Cancer Group of the Turkish Society of Oncology (TOG) (Appendix). The survey consisted of 17 questions regarding various parameters, including treatment planning and post-treatment follow-up. The first section addressed treatment preparation and simulation processes, the second section considered target volume delineation techniques, prescribed doses, and delivery schedules, while the third section addressed precautions and recommendations regarding vaginal side effects.

At present, there are 30 RT centers in Turkey, with an equipment needed to perform intracavitary HDR brachytherapy. The survey was created using an online survey program (www.SurveyMonkey.com), which generated a web-based link to the survey. The survey link and an invitation to voluntarily participate were emailed to the 66 members of the gynecological oncology subgroup, and the invitation was also posted on the website of the Turkish Society for Radiation Oncology (TROD). The survey was open between January $2^{\text {nd }}$ and February $12^{\text {th }}, 2018$, and took approximately 4 min to complete.

\section{Results}

\section{VBT preparation and simulation}

Among the 66 members of the TROD gynecological oncology sub-group, 57 radiation oncologists completed the survey (response rate, $86 \%$ ). The first section of the survey showed that computed tomography (CT)-based simulation was used for only the first fraction by $65 \%$ of the respondents, while $21 \%$ of respondents preferred CT-based planning for each fraction (Table 1). Approximately $47 \%$ of respondents used a urinary catheter to fill the bladder to some degree for each faction, while $35 \%$ of respondents did not use urinary catheters. Furthermore, $42 \%$ of respondents did not recommend completely fill-

Table 1. The preparation and simulation processes for vaginal cuff brachytherapy

\begin{tabular}{lccc} 
Procedures & $\begin{array}{c}\text { All } \\
\text { fractions }\end{array}$ & $\begin{array}{c}\text { First } \\
\text { fraction }\end{array}$ & $\begin{array}{c}\text { Not } \\
\text { recommended }\end{array}$ \\
\hline Urinary catheter & $47 \%$ & $18 \%$ & $35 \%$ \\
\hline Bowel preparation & $51 \%$ & - & $49 \%$ \\
\hline CT-based simulation & $21 \%$ & $65 \%$ & $14 \%$
\end{tabular}

Bowel preparation: any diet intervention or enema use before each application ing the bladder during VBT planning and delivery. Onehalf of the respondents reported using enema at every fraction to provide consistent rectal doses.

\section{Dose prescription and delivery schedules}

The prescribed doses were stratified according to the use of VBT alone or VBT with external RT. The most common schemes for VBT alone were $7 \mathrm{~Gy} \times 3$ fractions $(30 \%), 5.5 \mathrm{~Gy} \times 5$ fractions $(26 \%)$, and $6 \mathrm{~Gy} \times 5$ fractions

Table 2. Vaginal cuff brachytherapy dose and fractionation, and treated volumes for vaginal cuff brachytherapy. The questions related to preferred fraction schedules were asked in multiple choice design to assess whether more than one schedule could be in standard clinical use

\begin{tabular}{|c|c|}
\hline Parameter (No. of participants/No. of answers) & $\%$ \\
\hline Vaginal cuff BRT only $(n=57 / 66)^{\star}$ & $116^{\star}$ \\
\hline 7 Gy $\times 3$ fractions & 30 \\
\hline 5.5 Gy $\times 5$ fractions & 26 \\
\hline 6 Gy $\times 5$ fractions & 28 \\
\hline 5 Gy $\times 5$ fractions & 16 \\
\hline 7 Gy $\times 4$ fractions & 12 \\
\hline Other & 4 \\
\hline 45 Gy external RT + vaginal cuff BRT $(n=56 / 65)^{\star}$ & $116^{\star}$ \\
\hline 6 Gy $\times 3$ fractions & 34 \\
\hline 5 Gy $\times 3$ fractions & 50 \\
\hline 7 Gy $\times 3$ fractions & 21 \\
\hline 5 Gy $\times 4$ fractions & 9 \\
\hline 6 Gy $\times 2$ fractions & 2 \\
\hline Other & 0 \\
\hline 50.4 Gy external RT + vaginal cuff BRT $(n=56 / 60)^{*}$ & $107^{\star}$ \\
\hline 5 Gy $\times 3$ fractions & 32 \\
\hline 6 Gy $\times 3$ fractions & 30 \\
\hline 4 Gy $\times 3$ fractions & 18 \\
\hline 6 Gy $\times 2$ fractions & 16 \\
\hline 4 Gy $\times 4$ fractions & 4 \\
\hline Other & 7 \\
\hline Target volume for adenocarcinoma $(n=57)$ & $100^{+}$ \\
\hline First $4 \mathrm{~cm}$ cranially & 35 \\
\hline First $3 \mathrm{~cm}$ cranially & 33 \\
\hline Apical $1 / 3$ of vagina & 19 \\
\hline Entire cylinder & 13 \\
\hline Target volume for serous or clear cell histology $(n=57)$ & $100^{+}$ \\
\hline First $4 \mathrm{~cm}$ & 35 \\
\hline First $3 \mathrm{~cm}$ & 11 \\
\hline Entire cylinder & 38 \\
\hline Other & 16 \\
\hline
\end{tabular}

* The participants could indicate more than one answer according to their clin ical practice for the first 3 questions regarding dose schedules. Based on this multiple answers option, even 57 radiation oncologist answered the survey, more than 65 answers were notes in the results section; + these questions were designed as a single choice, so the participants could choose only the most suitable answer 
Table 3. Treatment schedules and post-treatment recommendations

\begin{tabular}{|c|c|}
\hline Parameter $(n=57)$ & $\%$ \\
\hline \multicolumn{2}{|l|}{ Fraction sequency of application } \\
\hline Everyday & 16 \\
\hline Every other days & 23 \\
\hline Every two days (twice in a week) & 53 \\
\hline Other & 8 \\
\hline \multicolumn{2}{|l|}{ Dose prescription } \\
\hline Surface of vaginal mucosa & 11 \\
\hline At $0.5 \mathrm{~cm}$ & 86 \\
\hline Other & 3 \\
\hline \multicolumn{2}{|c|}{ Timing of brachytherapy and chemotherapy } \\
\hline Before chemotherapy & 25 \\
\hline Between chemotherapy cycles & 30 \\
\hline After chemotherapy & 45 \\
\hline \multicolumn{2}{|l|}{ Timing for sexual intercourse } \\
\hline Immediately after treatment & 5 \\
\hline 1 week after treatment & 11 \\
\hline 3 week after treatment & 40 \\
\hline 6 week after treatment & 44 \\
\hline Other & 0 \\
\hline \multicolumn{2}{|l|}{ Vaginal dilatators or sexual intercourse } \\
\hline Once weekly & 78 \\
\hline No & 22 \\
\hline \multicolumn{2}{|l|}{ Estrogen-based vaginal gel } \\
\hline Yes & 68 \\
\hline No & 32 \\
\hline
\end{tabular}

(28\%) (Table 2). When the VBT was combined with external pelvic RT (45 Gy in 25 fractions), the most common VBT schemes were 5 Gy $\times 3$ fractions $(50 \%), 6$ Gy $\times 3$ fractions $(34 \%)$, and 7 Gy $\times 3$ fractions (21\%). When the VBT was combined with higher dose external RT (50.4 Gy in 28 fractions), the most common VBT schemes were 5 Gy $\times 3$ fractions $(32 \%), 6$ Gy $\times 3$ fractions $(30 \%)$, and 4 Gy $\times 3$ fractions (18\%). Approximately one-half of the respondents $(52 \%)$ reported using two applications per week. Majority of the respondents $(86 \%)$ reported that the dose was prescribed to $0.5 \mathrm{~cm}$ from the vaginal mucosa.

The VBT target volume was defined as the first $3 \mathrm{~cm}$ from the vaginal cuff in $33 \%$ of responses, the first $4 \mathrm{~cm}$ in $35 \%$ of answers, and the entire cylinder in $13 \%$ of responses. Furthermore, $19 \%$ of the respondents preferred treating the apical $1 / 3^{\text {rd }}$ of the vaginal mucosa. A change in the treated volume was made by $38 \%$ of the respondents for patients with serous or clear cell histology. Most of the respondents $(93 \%)$ agreed that brachytherapy should be performed after external RT for cases involving serous or clear cell histology. None of the respondents reported changing their dose preference according to histology. When VBT was combined with chemotherapy, $45 \%$ of the participants indicated that VBT was delivered after chemotherapy, while $45 \%$ of the respondents reported delivering the VBT before or between the chemotherapy cycles.

\section{Post-treatment recommendations}

Majority of the respondents provided some recommendation to prevent vaginal fibrosis and shortening after VBT alone or VBT combined with external RT. The recommended steps were use of vaginal dilatators (78\%) or resuming sexual intercourse at 6 weeks after treatment completion (44\%). Most of the respondents (68\%) did not recommend a treatment for vaginal dryness, although the use of a vaginal estrogen cream once per week was recommended by $32 \%$ of the respondents (Table 3).

\section{Discussion}

Randomized studies and guidelines regarding VBT have usually emphasized patients' selection and description of the treatment groups, and have defined VBT as a simple technique that is well tolerated and has minimal side effects [12]. Although published surveys of radiation oncologists have shown variability in the fractionation and planning parameters, most strategies have been aligned with the ABS recommendations $[7,8]$. However, there are no clear data regarding VBT strategies in Turkey, which motivated us to survey the TROD gynecological oncology sub-group regarding their current practices for using VBT to treat EC. Furthermore, we evaluated physicians' preferences regarding optional parameters that were not included in the recent American Brachytherapy Task Group Reports [13-19], such as rectum and bladder filling, and measures to prevent vaginal dysfunction. The distribution of responses indicated that CT-based planning was generally performed for the first fraction, a VBT scheme of 5 Gy $\times 3$ fraction was usually applied after external RT (at a dose of 45 Gy), the VBT was generally performed every 2 days, and the dose was prescribed to $0.5 \mathrm{~cm}$ from the vaginal mucosa. Common strategies for managing vaginal dryness, fibrosis, and shortening included weekly dilatator use, sexual intercourse, and weekly estrogen cream application.

Patient's anatomy and filling of the rectum and bladder have significant effects on the dose distribution, based on results from both dosimetric and prospective studies [15, 18-22]. Hung et al. performed CT-based dosimetric analyses of patients with an empty bladder and after bladder filling with $180 \mathrm{ml}$ of sterile water, which revealed that the distended bladder was associated with lower doses to the small bowel around the vaginal cuff, without significant changes in the doses to the bladder, rectum, or sigmoid colon [15]. Stewart et al. compared three bladder filling strategies for each VBT fraction and reported that an empty bladder was associated with lower bladder doses during vaginal cuff HDR brachytherapy [21]. Conflicting results were also observed in Turkish practice, as approximately one-half of the respondents preferred an empty bladder and the remaining ones preferred some degree of bladder filling.

The ABS survey published in 2004 showed that almost all respondents used radiographs for imaging and 
VBT planning for each session [7]. However, when similar questions were repeated in the 2014 survey, three-dimensional CT-based planning was preferred by $83.2 \%$ of the respondents, although $73.4 \%$ of them only used CT planning for the first fraction [8]. Martell et al. [10] subsequently surveyed ABS members in 2019 and reported that only $64 \%$ of respondents used CT for VBT planning, and only $33 \%$ of the respondents repeated the CT planning before each subsequent fraction. Our survey revealed that $65 \%$ of Turkish respondents used CT-based planning for the first fraction and $21 \%$ repeated the planning for every fraction, which is consistent with the reported use patterns among ABS members.

The ABS surveys have also showed diversity in the dose schedules and dose specifications regarding vaginal length and depth [7-11]. The 2003 ABS survey revealed that almost one-half of physicians used 15 Gy delivered in 3 fractions prescribed to $0.5 \mathrm{~cm}$ from the mucosa in patients treated using pelvic RT and VBT, and that the prescribed dose was increased to 21 Gy delivered in 3 fractions when VBT was used alone [7]. The 2014 survey also indicated that approximately one-half of respondents used the same schedule that was defined in the 2004 survey [10]. However, a 2009 survey of the Gynecologic Cancer Intergroup regarding external RT and VBT for EC revealed that there was no agreement regarding the brachytherapy dose, fractionation, or schedule [23]. In addition, although the ABS guidelines aimed to promote consistency between centers, there was only approximately $50 \%$ agreement regarding the dose scheme and vaginal length for the dose specification. Our results indicated that one-half of the Turkish radiation oncologists preferred 15 Gy in 3 fractions when the VBT was combined with external RT (45 Gy), although when VBT was used alone, the most common schemes were $21 \mathrm{~Gy}$ in 3 fractions, 27.5 Gy in 5 fractions, and 30 Gy in 5 fractions. Long-term results of the PORTEC-2 trial suggest that $21 \mathrm{~Gy}$ in 3 fractions is the standard of care, and the ongoing PORTEC-4 study will evaluate the effects of a schedule using 15 Gy in 3 fractions [24]; although that study was revised in 2016 and the first results will not be available until 2028. Nevertheless, the PORTEC-2 strategy (21 Gy in 3 fractions over 2 weeks; three fraction given within two weeks, not in one) has been prospectively validated as an effective local treatment with a low-rate of late vaginal toxicity (3\%) [25].

Long-term vaginal toxicities can include vaginal discharge, dryness, itching, bleeding, fibrosis, telangiectasias, stenosis, shortening or narrowing of the vagina, and dyspareunia [26]. The VBT factors that influence vaginal toxicity are dose-rate, fractionation, and length and depth of the treated vagina [13]. Local treatments after VBT can help improve vaginal tropism, elasticity, and lubrication [27]. Park et al. [28] evaluated intravaginal HDR brachytherapy for EC and reported that vaginal stenosis was not observed in $67 \%$ of patients, although they reported grade 1 stenosis in $26 \%$ of patients, grade 2 stenosis in $6 \%$ of patients, and grade 3 stenosis in $1 \%$ of patients. The risk of grade $\geq 1$ stenosis was independently related to the proportion of vagina receiving $>60 \%$ of the prescribed dose and a total dose of $>14$ Gy, while grade $\geq 2$ stenosis was independently predicted by nonuse of a vaginal dilator. Law et al. also reported that using a vaginal dilatator was effective for minimizing the risk of vaginal stenosis [29]. However, in contrast with the results from that prospective trial, a Cochrane review and another report provided conflicting evidence regarding the routine use of dilatators $[29,30]$. A small number of studies have evaluated topical therapies and described improved outcomes after the use of vaginal estrogen applications for acute and late toxicities, especially in terms of dyspareunia, alterations in the vaginal epithelium, and vaginal stenosis [31]. Our study showed that almost 70\% of the respondents recommended using a dilator at least once per week as well as estrogen creams based on specific vaginal symptoms. However, there are no widely accepted guidelines in Turkey and other countries regarding the recommended frequencies of dilatator or estrogen cream use. Therefore, studies are needed to clarify the optimal frequency and duration of their use as well as methods for improving adherence.

The present study has several limitations. First, the survey only received 57 responses, which corresponded to only $10 \%$ of all Turkish radiation oncologists. Nevertheless, it is important to note that we specifically targeted radiologists that specialize in treating gynecological cancers, which may strengthen our findings regarding routine practice in Turkey. Second, the questionnaire has not been validated in any other study. Third, the questions only addressed the VBT parameters, and did not consider the specific indications or details regarding external RT use. Therefore, a more detailed survey and the development of guidelines may help guide routine practice for managing early-stage and late-stage endometrial cancer.

Although several guidelines have been developed to standardize VBT treatment, there is substantial variability in the routinely used VBT parameters for both endometrioid and non-endometroid cancers [32]. Furthermore, different surveys have also indicated significant variability in treatment's recommendations as well as simulation and planning processes, when using VBT as adjuvant treatment for EC [7-11]. Our survey of the TROD gynecological oncology sub-group also showed similar variability in Turkey, which may be related to differences in institutional experience, infrastructure, and physicians' preference. This survey provides a starting point for better understanding Turkish practices, and we hope to perform additional studies to develop standardized national guidelines, which might be supported by a prospective multicenter study.

\section{Disclosure}

The authors report no conflict of interest.

\section{References}

1. Howlader N, Noone AM, Krapcho M et al. SEER Cancer Statistics Review, 1975-2016. National Cancer Institute. Bethesda, MD. https://seer.cancer.gov/csr/1975_2016/, based on November 2018 SEER data submission, posted to the SEER web site, April 2019. 
2. Nout RA, Smit V, Putter $\mathrm{H}$ et al. Vaginal brachytherapy versus pelvic external beam radiotherapy for patients with endometrial cancer of high-intermediate risk (PORTEC-2): an open-label, non-inferiority, randomised trial. Lancet 2010; 375: 816-823.

3. Modh A, Ghanem AI, Burmeister C et al. Trends in the utilization of adjuvant vaginal brachytherapy in women with early-stage endometrial carcinoma: Results of an updated period analysis of SEER data. Brachytherapy 2016; 15: 554-561.

4. Rossi PJ, Jani AB, Horowitz IR et al. Adjuvant brachytherapy removes survival disadvantage of local disease extension in stage IIIC endometrial cancer: a SEER registry analysis. Int J Radiat Oncol Biol Phys 2008; 70: 134-138.

5. Nag S, Erickson B, Parikh S et al. The American Brachytherapy Society recommendations for high-dose-rate brachytherapy for carcinoma of the endometrium. Int J Radiat Oncol Biol Phys 2000; 48: 779-790.

6. Small W, Jr., Beriwal S, Demanes DJ et al. American Brachytherapy Society consensus guidelines for adjuvant vaginal cuff brachytherapy after hysterectomy. Brachytherapy 2012; 11: 58-67.

7. Small W, Erickson B, Kwakwa F. American Brachytherapy Society survey regarding practice patterns of postoperative irradiation for endometrial cancer: Current status of vaginal brachytherapy. Int J Radiat Oncol Biol Phys 2005; 63: 15021507.

8. Harkenrider MM, Grover S, Erickson BA et al. Vaginal brachytherapy for postoperative endometrial cancer: 2014 Survey of the American Brachytherapy Society. Brachytherapy 2016; 15: 23-29.

9. Pereira EB, De B, Kolev V et al. Survey of current practice patterns in the treatment of early-stage endometrial cancer. Int J Gynecol Cancer 2016; 26: 341-347.

10. Martell K, Doll C, Barnes EA et al. Radiotherapy practices in postoperative endometrial cancer: A survey of the ABS membership. Brachytherapy 2019; 18: 741-746.

11. Cattari G, Delmastro E, Bresciani $S$ et al. Survey on gynecological cancer treatment by Piedmont, Liguria, and Valle d'Aosta group of AIRO (Italian Association of Radiation Oncology). J Contemp Brachytherapy 2016; 8: 128-134.

12. Arenas M, Sabater S, Gascon M et al. Quality assurance in radiotherapy: analysis of the causes of not starting or early radiotherapy withdrawal. Radiat Oncol 2014; 9: 260.

13. Harkenrider MM, Block AM, Alektiar KM et al. American Brachytherapy Task Group Report: Adjuvant vaginal brachytherapy for early-stage endometrial cancer: A comprehensive review. Brachytherapy 2017; 16: 95-108.

14. Hoskin PJ, Bownes P, Summers A. The influence of applicator angle on dosimetry in vaginal vault brachytherapy. $\mathrm{Br}$ J Radiol 2002; 75: 234-237.

15. Hung J, Shen S, De Los Santos JF et al. Image-based 3D treatment planning for vaginal cylinder brachytherapy: dosimetric effects of bladder filling on organs at risk. Int J Radiat Oncol Biol Phys 2012; 83: 980-985.

16. Iati G, Pontoriero A, Mondello $S$ et al. Three-dimensional treatment planning for vaginal cuff brachytherapy: dosimetric effects on organs at risk according to patients position. Brachytherapy 2014; 13: 568-571.

17. Patel MK, Cote ML, Ali-Fehmi R et al. Trends in the utilization of adjuvant vaginal cuff brachytherapy and/or external beam radiation treatment in stage I and II endometrial cancer: a surveillance, epidemiology, and end-results study. Int J Radiat Oncol Biol Phys 2012; 83: 178-184.

18. Sabater $S$, Arenas M, Berenguer R et al. Body mass index and doses at organs at risk in a Mediterranean population treated with postoperative vaginal cuff brachytherapy. Cancer Res Treat 2015; 47: 473-479.
19. Sabater S, Arenas M, Berenguer R et al. Dosimetric analysis of rectal filling on rectal doses during vaginal cuff brachytherapy. Brachytherapy 2015; 14: 458-463.

20. Guler OC, Onal C, Acibuci I. Effects of bladder distension on dose distribution of vaginal vault brachytherapy in patients with endometrial cancer. J Contemp Brachytherapy 2015; 6: 371-376.

21. Stewart AJ, Cormack RA, Lee $\mathrm{H}$ et al. Prospective clinical trial of bladder filling and three-dimensional dosimetry in high-dose-rate vaginal cuff brachytherapy. Int J Radiat Oncol Biol Phys 2008; 72: 843-848.

22. Ozdemir Y, Dolek Y, Onal C. Effects of vaginal cylinder position on dose distribution in patients with endometrial carcinoma in treatment of vaginal cuff brachytherapy. J Contemp Brachytherapy 2017; 9: 230-235.

23. Small W, Jr., Du Bois A, Bhatnagar S et al. Practice patterns of radiotherapy in endometrial cancer among member groups of the gynecologic cancer intergroup. Int J Gynecol Cancer 2009; 19: 395-399.

24. Wortman BG, Bosse T, Nout RA et al. Molecular-integrated risk profile to determine adjuvant radiotherapy in endometrial cancer: Evaluation of the pilot phase of the PORTEC-4a trial. Gynecol Oncol 2018; 151: 69-75.

25. Laliscia C, Delishaj D, Fabrini MG et al. Acute and late vaginal toxicity after adjuvant high-dose-rate vaginal brachytherapy in patients with intermediate risk endometrial cancer: is local therapy with hyaluronic acid of clinical benefit? J Contemp Brachytherapy 2016; 8: 512-517.

26. Park HS, Ratner ES, Lucarelli L et al. Predictors of vaginal stenosis after intravaginal high-dose-rate brachytherapy for endometrial carcinoma. Brachytherapy 2015; 14: 464-470.

27. Law E, Kelvin JF, Thom B et al. Prospective study of vaginal dilator use adherence and efficacy following radiotherapy. Radiother Oncol 2015; 116: 149-155.

28. Akbaba S, Oelmann-Avendano JT, Krug D et al. The impact of vaginal dilator use on vaginal stenosis and sexual quality of life in women treated with adjuvant radiotherapy for endometrial cancer. Strahlenther Onkol 2019; 195: 902-912.

29. Morris L, Do V, Chard J et al. Radiation-induced vaginal stenosis: current perspectives. Int J Womens Health 2017; 9: 273-279. 


\section{Appendix}

A survey of the Turkish Radiation Oncology Group regarding vaginal brachytherapy application

1. What dose fraction scheme do you prefer for high-dose-rate vaginal cuff brachytherapy alone?
a. 6 Gy $\times 5$ fractions
b. $4 \mathrm{~Gy} \times 6$ fractions
c. 7 Gy $\times 4$ fractions
d. 7 Gy $\times 3$ fractions
e. $5 \mathrm{~Gy} \times 5$ fractions
f. Other

2. What is the dose fractionation scheme you use for vaginal cuff brachytherapy with external radiotherapy (dose, $45 \mathrm{~Gy})$ ?
a. $5 \mathrm{~Gy} \times 4$ fractions
b. $7 \mathrm{~Gy} \times 3$ fractions
c. 6 Gy $\times 3$ fractions
d. $5 \mathrm{~Gy} \times 3$ fractions
e. 6 Gy $\times 2$ fractions
f. Other

3. What is the dose fractionation scheme you use for vaginal cuff brachytherapy with external radiotherapy (dose, $50.4 \mathrm{~Gy}$ )?
a. $4 \mathrm{~Gy} \times 4$ fractions
b. $6 \mathrm{~Gy} \times 3$ fractions
c. $5 \mathrm{~Gy} \times 3$ fractions
d. $4 \mathrm{~Gy} \times 3$ fractions
e. 6 Gy $\times 2$ fractions
f. Other

4. What is the frequency of brachytherapy application?
a. Every other day (3 days per week)
b. Every day
c. Once every three days
d. Twice per week
e. Other

5. Where do you define the dose prescription point?
a. Surface
b. Depth of $0.5 \mathrm{~cm}$
c. Other

6. Do you use a urinary catheter during the procedure?
a. Yes, at every fraction
b. Yes, only at the first fraction
c. No

7. Do you fill the bladder during vaginal brachytherapy delivery?
a. No
b. Yes, specific volume for each patient
c. Yes, $10 \mathrm{cc}$
d. Yes, $50 \mathrm{cc}$
e. Yes, $100 \mathrm{cc}$
f. Yes, $150 \mathrm{cc}$
g. Other

8. Do you recommend any bowel preparation?
a. Yes, at every fraction
b. Yes, only at the first fraction
c. No

9. Do you use computed tomography-based planning?
a. Yes, at every fraction
b. Yes, only at the first fraction
c. No

10. How do you define the length of the vaginal target for dose prescription (endometrial histology)?
a. First $3 \mathrm{~cm}$
b. First $4 \mathrm{~cm}$
c. Throughout the length of the cylinder
d. Other (please define)

11. How do you define the length of the vaginal target for dose prescription (non-endometrial histology)?
a. First $3 \mathrm{~cm}$
b. First $4 \mathrm{~cm}$
c. Throughout the length of the cylinder
d. Other (please define)

12. Do you use vaginal brachytherapy for serous or clear cell histology?
a. Yes
b. No

13. Are the indications and fraction schedules the same as that for endometrial cancers?
a. Yes
b. No

14. What is the timing of vaginal brachytherapy for patients who are receiving chemotherapy?
a. Before the start of chemotherapy
b. Between chemotherapy cycles
c. After the last chemotherapy cycle

15. When do you recommend resuming sexual intercourse after treatment?
a. Any time
b. One week after the end of treatment
c. Three weeks after the end of treatment
d. Six weeks after the end of treatment
e. Other

16. Do you provide recommendations regarding the use of dilators and/ or sexual intercourse after treatment?

a. Sexual intercourse or dilator use once per week

b. No

17. Do you recommend estrogen-based cream for treating vaginal dryness?
a. No
b. Yes, applied once per week 